\title{
Evaluation of preparation times of WaveOne Gold reciprocating instruments compared to two analogous counterparts
}

SADJ June 2021, Vol. 76 No. 6 p315 - p319

C Victor ${ }^{1}$, PJ van der Vyver ${ }^{2}$, M Vorster ${ }^{3}$, F Paleker $^{4}$, ZI Vally $^{5}$

\begin{abstract}
Manufacturers are constantly developing new products to optimise endodontic treatment. These newer file systems are often associated with increasing expenditure of instrumentation and can affect the cost effectiveness of root canal treatment. Recently, companies have emerged that claim to have successfully reproduced many of the more established endodontic file systems manufactured by Dentsply Sirona (Ballaigues, Switzerland).
\end{abstract}

EdgeEndo (Albuquerque, New Mexico, USA) and PacDent (Brea, CA, USA), which manufacture files similar in design to that of Dentsply Sirona, claim that they are similar and sell them at a lower price. A performance comparison of the replica file systems to their original is of clinical importance.

Author affiliations:

1. Christiaan Victor: BChD, PG Dip Dent (Endo)(Pret), PG Dip Dent (Impl), MSc(Dent), Department of Odontology, School of Dentistry, University of Pretoria, Pretoria, South Africa.

ORCID Number: 0000-0002-7213-9760

2. Peet J van der Vyver: $B C h D, P G$ Dip Dent (Endo), PG Dip Dent (Aesthet Dent), MSc, PhD (Pret), Department of Odontology, School of Dentistry, University of Pretoria, Pretoria, South Africa. ORCID Number: 0000-0003-1951-6042

3. Martin Vorster: BChD, PG Dip Dent (Endo), MSc (Pret), Department of Odontology, School of Dentistry, University of Pretoria, Pretoria, South Africa.

ORCID Number: 0000-0003-4470-1530

4. Farzana Paleker: BChD (Stell), Dip Odont (Endo), MSc (Pret), Department of Odontology, School of Dentistry, University of Pretoria, Pretoria, South Africa.

ORCID Number: 0000-0002-5446-309X

5. Zunaid I Vally: BDS, MDent (Prosthodontics)(Wits), Department of Odontology, School of Dentistry, University of Pretoria, Pretoria, South Africa.

ORCID Number: 0000-0002-2718-4706

Corresponding author: Peet $\mathrm{J}$ van der Vyver:

Department of Odontology, School of Dentistry, University of Pretoria,

Pretoria, South Africa.

Email: peetv@iafrica.com

Author contributions:

1. Christiaan Victor: Contributed to the data collection and analysis, scientific writing, and proofreading of the manuscrip - $20 \%$

2. Peet $\mathbf{J}$ van der Vyver: Contributed to the data analysis, scientific writing and proofreading of the manuscript - 35\%

3. Martin Vorster: Contributed to the scientific writing and proofreading of the manuscript - $15 \%$

4. Farzana Paleker: Contributed to the scientific writing and proofreading of the manuscript - $15 \%$

5. Zunaid I Vally: Contributed to the scientific writing and proofreading of the manuscript - $15 \%$
The aim of this ex vivo study was to compare the total glide path and canal preparation times of WaveOne Gold Glider (Dentsply Sirona) combined with the Primary WaveOne Gold (Dentsply Sirona), Edge GlidePath (Edge Endo, Albuquerque, New Mexico, USA) followed by the Primary EdgeOne Fire (EdgeEndo); and One File G Glide Path (Pac-Dent, Brea, CA, USA) file combined with the Primary One File G (Pac-Dent) Shaping file.

Sixty curved untreated canals of extracted, human, mandibular molars were randomly divided into three groups of 20 canals each for mechanical glide path enlargement and root canal shaping. Group 1 (WaveOne Gold Glider + Primary WaveOne Gold); Group 2 (Edge GlidePath + Primary EdgeOne Fire); and Group 3 (One File G Reciprocating Glide Path File + Primary One File G Reciprocating shaping file).

The total time taken to prepare a glide path and to complete the root canal preparation of each canal was recorded (in seconds) by means of an iPhone stopwatch (Apple Inc., Cupertino, California). The time taken to change files was not recorded. Throughout the instrumentation process, RC Prep was used as a lubricant, and $5 \mathrm{~mL} 3 \%$ sodium hypochlorite was used as irrigation solution.

Mean and standard deviations were determined for each group, and analysis of variance was used to statistically compare the mean glide path preparation times for the three groups.

The fastest final canal preparation time was achieved by WOGG/PWOG $(41.78 \pm 10.58 \mathrm{~s})$, followed by OFGP/ POFS (42.02 $\pm 12.16 \mathrm{~s})$ and then EGP/PEOF (42.49 \pm $10.44 \mathrm{~s})$. There were no statistically significant differences between the canal preparation times of the three combination groups ( $\mathrm{p}>0.05)$.

\section{INTRODUCTION}

Thermomechanical processes have resulted in the development of nickel-titanium (NiTi) endodontic glide path and shaping files with increased flexibility and fatigue resistance compared to their predecessors. Companies 
are now developing analogous instrumentation systems that are similar in form and function to their competitors' but are constructed from differing proprietary heat-treated NiTi.

The preparation of a glide path prior to the introduction of rotary $\mathrm{NiTi}$ instruments is a standard adjunct to ensure more safety during root canal instrumentation. ${ }^{1}$ A glide path can be defined as a smooth, radicular tunnel from the canal orifice to the physiologic terminus of the root canal. ${ }^{2}$ Varela-Patiňo et al. ${ }^{3}$ found that fewer instrument fractures occurred when a wide and smooth-walled glide path was created and the canal was pre-flared before canal preparation with rotary files. ${ }^{3}$

Glide path preparation allows for an understanding and appreciation of the original canal anatomy, renders the canal patent to receive rotary files, and permits a more effective and safer action during root canal shaping. ${ }^{4,5}$ Once established, successful glide path preparation can reduce torsional stresses and increase the life span of a rotary instrument by up to 6 times. ${ }^{5}$

A study by Patiño et al., ${ }^{3}$ showed that the incidence of instrument separation was significantly reduced in canals in which preparation was preceded by proper glide path preparation. A separate study showed a higher incidence of distortion and separation of NiTi files in the absence of initial glide path preparation. ${ }^{6}$

NiTi rotary PathFiles (Dentsply Sirona, Ballaigues, Switzerland) were introduced in 2009 to facilitate glide path preparation. A study by Cantatore et al., ${ }^{7}$ showed that PathFiles can prepare a glide path with fewer irregularities and better conservation of original canal anatomy, even after canal preparation by inexperienced users. In recent years, single-file rotary and reciprocating glide path preparation systems have been introduced.

The use of NiTi shaping files in a reciprocating motion is a recent innovation, with manufacturers claiming increased resistance to instrument separation compared to rotary instrumentation, and to adequately shape and preserve the anatomy of root canal systems. ${ }^{8}$

Although some studies indicate more debris accumulation with the reciprocating technique, ${ }^{9}$ compared to multiple consecutive rotary files, overall cleaning effectiveness has been shown to be equal or comparable ${ }^{10,11}$ and, in some, better $^{12}$ than traditional rotary systems.

Several studies have also shown that the reduction of the bacterial load was found to be similar in both reciprocating and rotary systems. ${ }^{13-15}$

In a review article by Plotino et al., ${ }^{8}$ they conclude that reciprocating files have a lower incidence of dentinal defects and cracks. However, a study by Deus et al., ${ }^{16}$ observed no association between these cracks and shaping with single-file reciprocating or multi-file rotary systems.

The aim of this ex vivo study was to compare the total glide path and canal preparation times of WaveOne Gold Glider (Dentsply Sirona) combined with the Primary WaveOne Gold (Dentsply Sirona), Edge GlidePath (EdgeEndo,
Albuquerque, New Mexico, USA) followed by the Primary EdgeOne Fire (EdgeEndo); and One File G Glide Path (PacDent, Brea, CA, USA) file combined with the Primary One File G (Pac-Dent) Shaping file. The null hypothesis tested was that there are no differences in canal preparation times between the three groups. Currently, there are no published studies comparing the total canal preparation times of these analogous shaping systems in curved canals of mandibular molars.

\section{MATERIALS AND METHODS}

\section{Specimen preparation}

Extracted mandibular first molar teeth with curved mesial roots containing two separate canals and mesial apical foramina were collected for this study. Radiographs (Carestream Health Inc., NY State, USA) were used to select a total of 60 previously untreated mesiobuccal canals with closed apices and curvatures of $25^{\circ}$ to $35^{\circ}$ according to the Schneider method. ${ }^{17}$ The 60 specimens were engraved from 1 to 60 and then randomly divided into three experimental instrumentation groups of 20 each using an online randomiser tool (Research Randomizer version 4.0) (Urbaniak \& Pious 2011). ${ }^{18}$

All specimens were mounted in an FKG vice (FKG Dentaire, La Chaux-de-Fonds, Switzerland) designed for endo training, to simulate clinical situations and standardise preparation conditions. After access cavity preparation, working length (WL) was determined by deducting $0.5 \mathrm{~mm}$ from the length of the canal measured to the major apical terminus under 10 times magnification using a surgical microscope (Zumax Medical Co. Ltd, Suzhou, China).

The mesio-buccal canals were located and explored with a size 08 Senseus K-Flexofile (Dentsply Sirona) and canals were negotiated to patency. An initial manually reproducible micro-glide path was prepared by negotiating a size 08 Senseus K-Flexofile to WL with increasing amplitudes of $1-3 \mathrm{~mm}$. This process was repeated using a pre-curved size 10 Senseus K-Flexofile (Dentsply Sirona). Reproducibility was checked by the ability to place the Senseus K-Flexofile 3-4 mm short of working length and pushing it to full working length without any obstruction by means of light finger pressure.

\section{Glide path preparation and root canal shaping}

Glide path preparation and root canal shaping were carried out by the same operator and new files were used for each tooth. RC Prep (Premier, Pennsylvania, USA) was used as a lubricating agent during the glide path enlargement and 3.5\% sodium hypochlorite was used for canal irrigation after the use of each file. Patency was maintained throughout the glide path and root canal preparations with an ISO size 08 Senseus K-Flexofile.

\section{Group WOGG/PWOG $(\mathrm{n}=20)$}

The X-Smart IQ endodontic motor (Dentsply Sirona) was used in reciprocation mode for both glide path preparation with the Wave One Gold Glider (WOGG), and shaping with the Primary Wave One Gold (PWOG). This was done on the WaveOne Gold setting according to the manufacturer's instructions. 


\section{Group OFGP/POFG $(\mathrm{n}=20)$}

The X-Smart IQ endodontic motor (Dentsply Sirona) was used in reciprocation mode for both glide path preparation with the One File G Glide Path file (OFGP), and shaping with the Primary One File G Shaping file (POFS). This was done on the WaveOne Gold setting according to the manufacturer's instructions.

\section{Group EGP/PEOF $(n=20)$}

The X-Smart IQ endodontic motor (Dentsply Sirona) was used in rotary mode (300rpm, 3Ncm - ProGlider settings) for glide path preparation with the Edge GlidePath (EGP), and shaping with the Primary Edge One Fire (PEOF) in reciprocation. This was done on the WaveOne Gold setting according to the manufacturer's instructions.

\section{Data collection}

Each glide path or root canal preparation file was only used to prepare one canal before being discarded. The total time taken to prepare a glide path and to complete the root canal preparation of each canal was recorded (in seconds) by means of an iPhone stopwatch (Apple Inc., Cupertino, California). The time taken to change files was not recorded. Throughout the instrumentation process, RC Prep was used as a lubricant, and $5 \mathrm{ml} 3 \%$ sodium hypochlorite was used as irrigation solution.

\section{Statistical analysis}

Mean and standard deviations were determined for each group, and analysis of variance was used to statistically compare the mean glide path preparation times for the three groups. Statistical procedures were performed on SAS Release 9.3 (SAS Institute Inc, Cary, NC) running under Microsoft Windows (Micro- soft Corp, Redmond, WA) for a personal computer.

\section{RESULTS}

The mean and standard deviation values for the glide path preparation and final canal shaping times for the three different groups are presented in Table 1. The fastest final canal preparation time was achieved by WOGG/PWOG (41.78 $\pm 10.58 \mathrm{~s})$, followed by OFGP/POFS $(42.02 \pm 12.16 \mathrm{~s})$ and then EGP/PEOF (42.49 $\pm 10.44 \mathrm{~s})$. There were no statistically significant differences between the canal preparation times of the three combination groups $(p>0.05)$.

\section{DISCUSSION}

The total canal preparation time for three glide path preparation instruments and their associated shaping systems were investigated in mesio-buccal root canals of mandibular molars with moderate canal curvatures of between $25^{\circ}$ and $35^{\circ}$.
Each instrument was used in a reciprocating motion except for the EGP, which was used in continuous rotation before final shaping with the Primary EOF. Recently EdgeEndo launched its reciprocating glide path file, EdgeOne Fire GlidePath, which was not available at the time this research was undertaken.

The WaveOne Gold Glider (Dentsply Sirona) is a single glide path file with an ISO 15 tip size, variable taper from $2 \%$ at D0 to $6 \%$ at D16, a parallelogram-shaped crosssection, and a semi-active tip. WaveOne Gold (Dentsply Sirona) is a shaping system characterized by an alternating offset parallelogram-shaped cross-section design with two $85^{\circ}$ cutting edges. Both these systems are manufactured from Gold-Wire and are used in reciprocation.

The Edge GlidePath file (EdgeEndo) is a variable tapered single rotary glide path file with an ISO 19 tip size, a triangular cross-section, non-cutting tip, and a progressive taper with a $15 \mathrm{~mm}$ cutting length. EdgeOne Fire (EdgeEndo) is a reciprocating shaping system similar to WaveOne Gold. Both the EdgeOne Fire and Edge GlidePath systems are manufactured from a new proprietary heattreated NiTi referred to as "FireWire". ${ }^{19}$ The One File G Reciprocating File System (Pac-Dent) consists of a single glide path file and four shaping files.

The One File G Glide Path file (Pac-Dent) has an ISO 15 tip, 2\% taper, and a parallelogram-shaped cross-section. One File G Shaping files (Pac-Dent) each have a parallelogram-shaped cross-section, constant helical angle of $24^{\circ}$ along the active length of the instrument and two $80^{\circ}$ cutting edges and are used with the same handpiece settings as WaveOne Gold. The One File G Glide Pathand Shaping files are made using proprietary heat-treated $\mathrm{NiTi}$ wire and have roundly tapered guide tips without any cutting edges.

In the present study the total time taken to prepare a glide path and shape each canal was recorded (in seconds). There were no statistically significant differences in preparation times between the three combination groups in this study.

Several studies have compared single and multiple instruments in curved canals and have concluded that single file systems are significantly faster. ${ }^{12,20,21}$ In a study by Vorster et al., ${ }^{22}$ glide path preparation times of WOGG in a reciprocation motion were compared to that of K-Files and PathFiles in a rotary motion. WOGG showed statistically significantly faster glide path preparation times compared with both the K-file and the PathFile preparation groups. The authors attributed the results to the multiple instrument use in each of the other two groups compared to the WOGG group, which consisted of a single instrument.

\begin{tabular}{|c|c|c|c|c|}
\hline Value of $K$ & Strength of agreement & Value of $\mathbf{K}$ & Strength of agreement & Value of $\mathbf{K}$ \\
\hline WOGG/PWOG & $41.78^{a}$ & 10.58 & 25.32 & 64.66 \\
\hline EGP/PEOF & $42.49^{a}$ & 10.44 & 25.70 & 57.49 \\
\hline OFGRG/POFGR & $42.02^{a}$ & 12.16 & 23.71 & 68.68 \\
\hline
\end{tabular}


Some of the studies examining preparation times favour reciprocation, ${ }^{23}$ while others claim that single files used in rotation are faster. ${ }^{24} \mathrm{~A}$ study examined the shaping ability and preparation times of different single-file NiTi systems in rotation and reciprocation. ${ }^{25}$ In this study by Hwang et al., ${ }^{25}$ single Mtwo (VDW, Munich, Germany) and Reciproc (VDW) shaping files were used after glide path preparation with a size $15 \mathrm{~K}$-File and no differences in preparation times were found between the shaping groups. A separate study examined the shaping ability of different NiTi systems in simulated S-shaped canals with and without glide path preparation, and concluded that glide path preparation exerted no significant effect on preparation times of these canals. ${ }^{26}$

In a study by D'Amario et al., ${ }^{27}$ they compared the canal preparation time of One Shape (MicroMega, Besancon, France), Reciproc and WaveOne preparation systems after glide path preparation with a size $10 \mathrm{~K}$-File. They found no clinically relevant differences in preparation times between the three single file systems. Their recorded times were much higher than that of the current study. This could be attributed to the curvature of their tested specimens or the fact that the present study incorporated glide path files, which decreased the total shaping times.

In this study, preparation times were similar for all three combination groups. These single-file glide path and shaping systems are appealing for use in the clinical setting because of their reduced overall canal shaping time, potential low cost, prevention of cross-contamination, and easy clinical application.

\section{CONCLUSION}

Within the limitations of this study, it can be concluded that all three groups presented with similar preparation times, and no statistically significant differences were noted ( $p>0.05)$.

The limited information on EdgeEndo and One File G systems in the literature made it impossible to compare the results obtained in this study with other studies. To date, no paper has been published on the preparation times of these file combinations. It is however recommended that further studies are needed to evaluate these endodontic glide path and shaping systems clinically.

\section{References}

1. Mounce R. Endodontics-An Excellent Glide Path, the Road to Smoother Endodontics. Oral Health. 2004; 94(3): 51-8.

2. West J. Manual versus mechanical endodontic glidepath Dent. Today. 2011; 30(1): 136-45.

3. Patiño PV, Biedma BM, Liébana CR, Cantatore G, Bahillo JG. The influence of a manual glide path on the separation rate of NiTi rotary instruments. J Endod. 2005; 31(2): 114-6.

4. Knowles Kl, Hammond NB, Biggs SG, Ibarrola JL. Incidence of instrument separation using LightSpeed rotary instruments. J Endod. 2006; 32(1): 14-6.

5. Berutti E, Negro AR, Lendini M, Pasqualini D. Influence of manual preflaring and torque on the failure rate of ProTaper rotary instruments. J Endod. 2004; 30(4): 228-30.

6. Shen Y, Haapasalo M, Cheung GS-p, Peng B. Defects in nickel-titanium instruments after clinical use. Part 1: Relationship between observed imperfections and factors leading to such defects in a cohort study. J Endod. 2009; 35(1): 129-32.

7. Cantatore G, Berutti E, Castellucci A. The pathfiles: a new series of rotary nickel titanium instruments for mechanical pre-flaring and creating the glide path. Oral Health. 2010; 100(10): 66-8.

8. Plotino G, Ahmed HMA, Grande NM, Cohen S, Bukiet F. Current assessment of reciprocation in endodontic preparation: a comprehensive review - part II: properties and effectiveness. J Endod. 2015; 41(12): 1939-50.

9. Robinson JP, Lumley PJ, Cooper PR, Grover LM, Walmsley AD. Reciprocating root canal technique induces greater debris accumulation than a continuous rotary technique as assessed by 3 -dimensional micro-computed tomography. J Endod. 2013; 39(8): 1067-70.

10. Amaral P, Forner L, Llena C. Smear layer removal in canals shaped with reciprocating rotary systems. J Clin Exp Dent. 2013; 5(5): e227

11. Dietrich MA, Kirkpatrick TC, Yaccino JM. In vitro canal and isthmus debris removal of the self-adjusting file, $\mathrm{K} 3$, and WaveOne files in the mesial root of human mandibular molars. J Endod. 2012; 38(8): 1140-4.

12. Bürklein S, Hinschitza K, Dammaschke T, Schäfer E. Shaping ability and cleaning effectiveness of two single-file systems in severely curved root canals of extracted teeth: Reciproc and WaveOne versus Mtwo and ProTaper. Int Endod J. 2012; 45(5): 449-61.

13. Machado $M$, Nabeshima $C$, Leonardo $M$, Reis F, Britto $M$, Cai S. Influence of reciprocating single-file and rotary instrumentation on bacterial reduction on infected root canals. Int Endod J. 2013; 46(11): 1083-7.

14. Nabeshima CK, Caballero-Flores $H$, Cai S, Aranguren J, Britto MLB, de Lima Machado ME. Bacterial removal promoted by 2 single-file systems: WaveOne and One Shape. J Endod. 2014; 40(12): 1995-8.

15. Siddique R, Nivedhitha MS. Effectiveness of rotary and reciprocating systems on microbial reduction: A systematic review. JCD. 2019; 22(2): 114

16. De-Deus G, Silva EJNL, Marins J, et al. Lack of causal relationship between dentinal microcracks and root canal preparation with reciprocation systems. J. Endod. 2014; 40(9): 1447-50.

17. Schneider SW. A comparison of canal preparations in straight and curved root canals. Oral Surg. Oral Med. Oral Pathol. 1971; 32(2): 271-5.

18. Urbaniak G, Plous S. Research Randomizer v4. 0. 20132016.

19. Tomer AK, Miglani A, Sahni S, Goud BV, Vaidya S, Kumari A. Comparison of Efficacy of Three Ni-Ti Instruments in Removal of Gutta-Percha from Root Canal during Retreatment - An In Vitro Study. IOSR. J Dent Med Sci. 2017: 16, 32-7.

20. You S-Y, Bae K-S, Baek S-H, Kum K-Y, Shon W-J, Lee W. Lifespan of one nickel-titanium rotary file with reciprocating motion in curved root canals. J Endod. 2010; 36(12): 1991-4. 
21. Paqué F, Zehnder M, De-Deus G. Microtomography-based comparison of reciprocating single-file F2 ProTaper technique versus rotary full sequence. J Endod. 2011; 37(10): 1394-7.

22. Vorster M, van der Vyver PJ, Paleker F. Influence of glide path preparation on the canal shaping times of WaveOne Gold in curved mandibular molar canals. J Endod. 2018; 44(5): 853-5.

23. Bürklein S, Benten S, Schäfer E. Shaping ability of different single-file systems in severely curved root canals of extracted teeth. Int Endod J. 2013; 46(6): 590-7.

24. Saber S, Nagy M, Schäfer E. Comparative evaluation of the shaping ability of $W$ ave One, Reciproc and One Shape single-file systems in severely curved root canals of extracted teeth. Int Endod J. 2015; 48(1): 109-14.
25. Hwang Y-H, Bae K-S, Baek S-H, et al. Shaping ability of the conventional nickel-titanium and reciprocating nickel-titanium file systems: a comparative study using micro-computed tomography. J Endod. 2014; 40(8): 1186-9.

26. Bürklein S, Poschmann T, Schäfer E. Shaping ability of different nickel-titanium systems in simulated S-shaped canals with and without glide path. J Endod. 2014; 40(8): 1231-4.

27. D'Amario M, De Angelis F, Mancino M, Frascaria M,

Capogreco M, D'Arcangelo C. Canal shaping of different single-file systems in curved root canals. J Dent Sci. 2017; 12(4): 328-32.

\section{Do the CPD questionnaire on page 383}

The Continuous Professional Development (CPD) section provides for twenty general questions and five ethics questions. The section provides members with a valuable source of CPD points whilst also achieving the objective of CPD, to assure continuing education. The importance of continuing professional development should not be underestimated, it is a career-long obligation for practicing professionals.

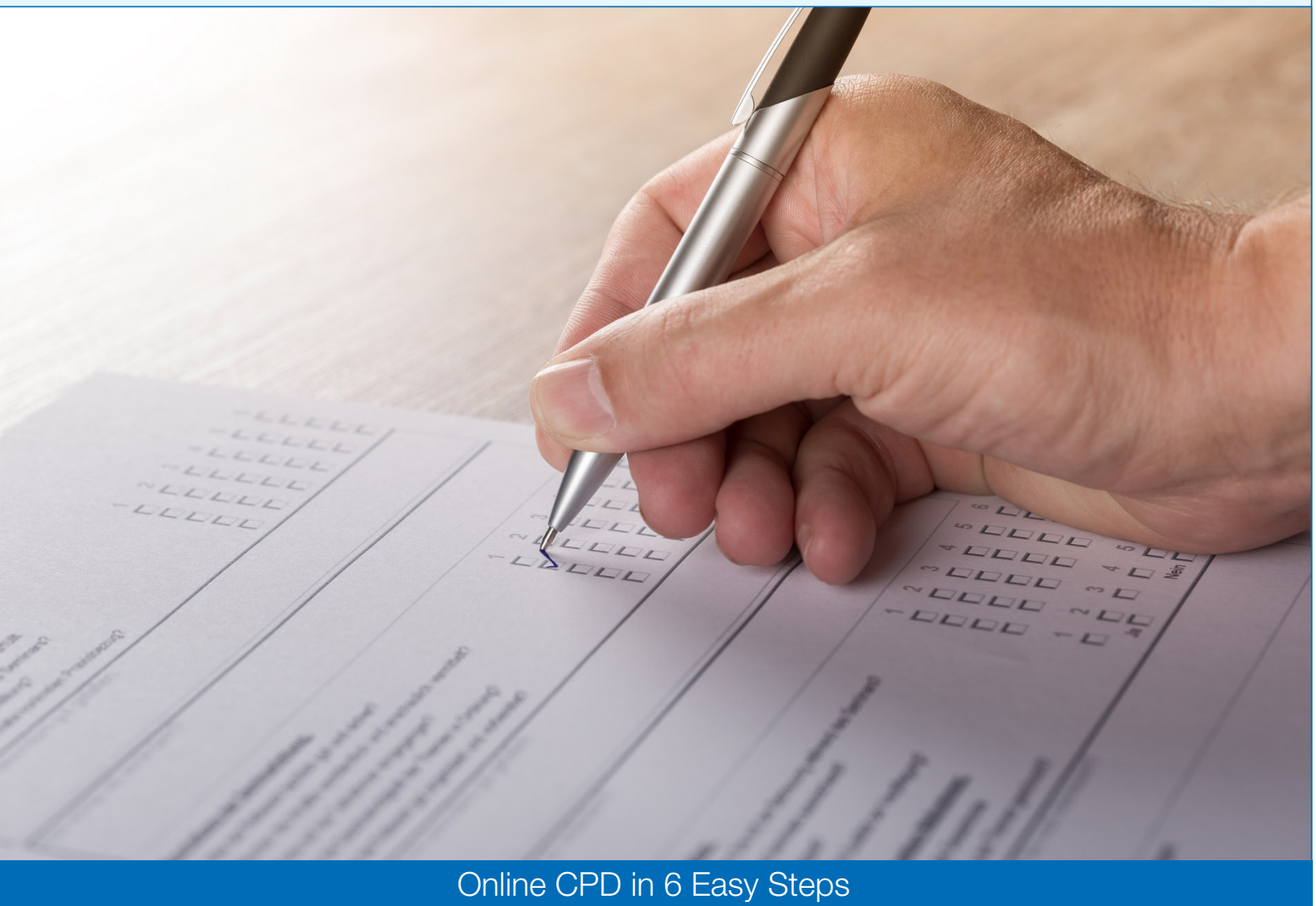

1 Go to the SADA website www.sada.co.za.

2 Log into the 'member only' section with your unique SADA username and password.

3 Select the CPD navigation tab.

4 Select the questionnaire that you wish to complete.

5 Enter your multiple choice answers. Please note that you have two attempts to obtain at least $70 \%$.

6 View and print your CPD certificate. 